\title{
Metáforas visuales en los mundos virtuales. El caso de NANEC 2010/11.
}

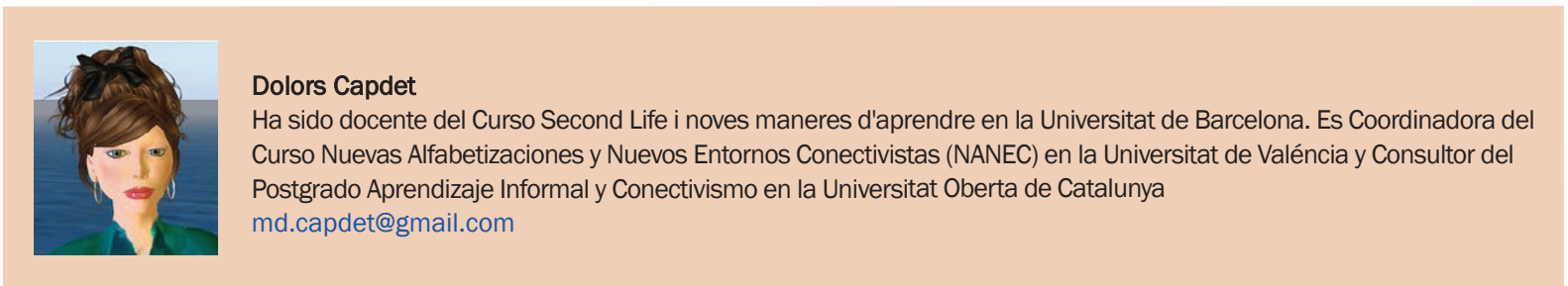

|Fecha presentación: 19/04/2011 | Aceptación: 14/06/2011 |Publicación: 21/06/2011

\begin{abstract}
Resumen
Antes de la invención de la imprenta la narración oral de historias era la gran transmisora del conocimiento. La imprenta otorgó velocidad y perennidad a la narración, ampliando el tiempo para su reflexión. Con Internet se fragmenta la secuencialidad del mensaje y es posible crear nuevas realidades que pueden tener o no su referente en el mundo real. Los mundos virtuales son un claro ejemplo de ello.
\end{abstract}

Palabras clave: NANEC2010, metáforas visuales, mundos virtuales, Second Life, tutorías, sesiones síncronas, e-learning

\section{Resum}

Abans de la invenció de la impremta la narració oral d'històries era la gran transmisora del coneixement. La impremta va atorgar velocitat i perennitat a la narració, ampliant el temps per a la seva reflexió. Amb Internet es fragmenta la seqüèncialitat del missatge i és possible crear noves realitats que poden tenir o no el seu referent al món real. Els mons virtuals en són un clar exemple.

Paraules clau: NANEC2010, metáforas visuales, mundos virtuales, Second Life, tutorías, sesiones síncronas, e-learning

\section{Abstract}

Before the invention of printing, the storytelling was the great transmitter of knowledge. The print brings speed and continuity to narrative and extending the time for their reflection. With Internet is fragmented the message sequentiality and may be create new realities with referent in the real world or not. Virtual worlds are a clear example.

Keywords: NANEC2010, metáforas visuales, mundos virtuales, Second Life, tutorías, sesiones síncronas, e-learning 


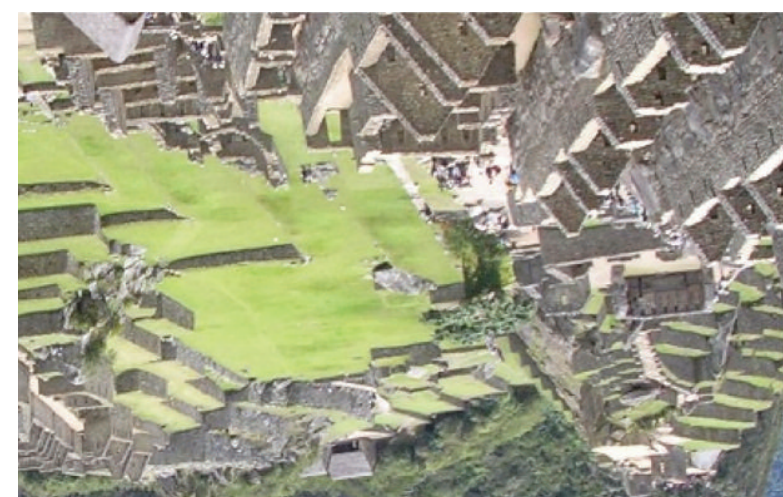

Figura 1. Machu Pichu, Perú. Virtualizado por la USMP.

Hay consenso en que la construcción de relatos constituye una estructura básica de significación que transforma la experiencia humana en conocimiento.

Las personas dan significado a su vida contando sus experiencias (White 1996), construyendo así su propia identidad (Rosenwald y Ochberg 1992), aunque si la narración no se aproxima a las formas convencionales, el relato deja de tener sentido (Gergen 1996), de lo que se deduce que la comprensión del mundo por parte de cada sujeto está en función de los relatos a los que tiene acceso y con los que interactúa de forma práctica.

La narración puede ser oral, escrita, visual y todas las derivaciones de ellas que la tecnología permite. Por ello es interesante el punto de vista de Drebray (1998) que contempla los objetos no como imágenes sino como apropiaciones de la mirada, describiendo tres fases (las denomina mediásferas) que aunque tienen su espacio en el tiempo conviven sin conflictos en el momento actual:

- Logoesfera, era simbólica en la que no se valora la forma creada, sino lo que representa (desde la invención de la escritura hasta la de la imprenta)

- Grafoesfera, que representa una creatividad que reafirma la individualidad y, a la vez, implica el reconocimiento por parte de la colectividad (desde la invención de la imprenta hasta la de la televisión en color).

- Videoesfera, era en la que la imagen tiene valor por

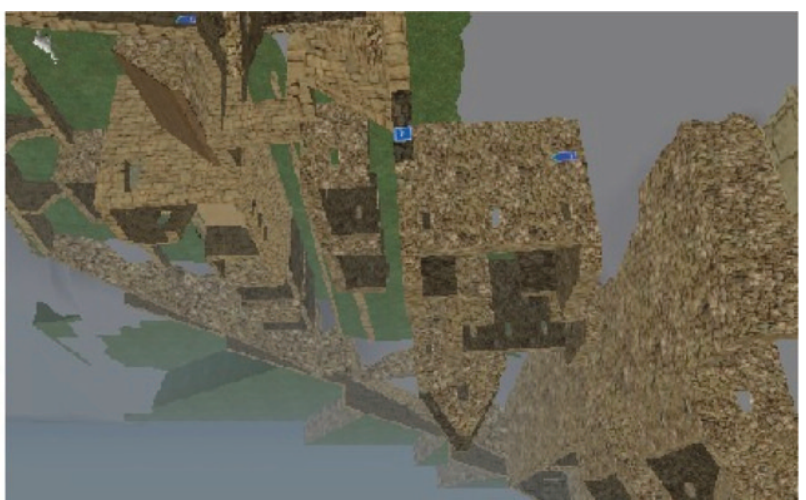

si misma independientemente de su vinculación con la realidad. En este aspecto, Debray considera que, desde el surgimiento del vídeo, materialmente ya no hay imagen sino señal eléctrica, lo que produce un cambio de concepto importante, porque se hace innecesario que la imagen copie la realidad. Ahora el hombre puede recrear un mundo que no tiene una referencia palpable y real.

Efectivamente es así. Internet y los mundos virtuales son prueba de ello.

\section{Representaciones a modo de metáforas visuales}

Los mundos virtuales se basan en la creación de objetos tridimensionales que constituyen una metáfora visual de la realidad, es decir, una representación de un sistema de entidades del mundo físico (calles, ríos, escuelas,...) a través de los atributos visuales específicos de un sistema sígnico (código visual) que las convierte en elementos reconocibles para el usuario, permitiéndole adoptar un comportamiento similar al que tendría en el contexto real (Figuras 1 y 2).

Procesar y comprender una representación o metáfora visual requiere la capacidad de explicitar algunos de sus mecanismos implícitos y de invertir el proceso tradicional de aprendizaje mediante la asociación de un objeto a un signo que lo representa, ya que, en una representación o metáfora visual virtual, es el signo el que remite al objeto de referen-

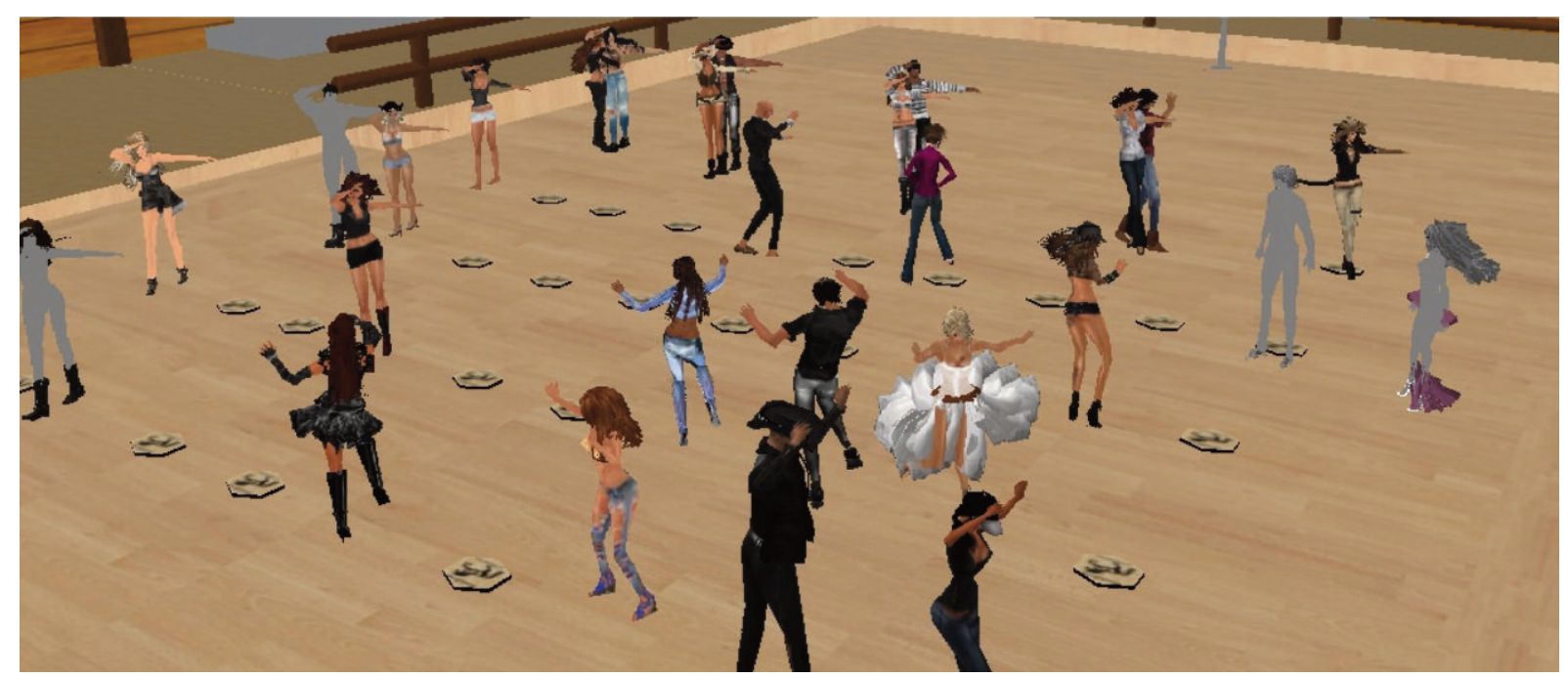

Figura 2. Black Horse Country. 
cia, y no a la inversa. Dada la cualidad transformadora de la realidad que tiene toda metáfora, si existe una vinculación previa objeto/signo es necesario saber deshacerla y/o rehacerla para tener una mayor perspectiva y poder obtener un nuevo significado entre todos los que son posibles.

En este sentido, dado que los mundos virtuales son una representación de una cosa en términos de otra; para obtener los significados de las metáforas es necesario tener en cuenta que estas representaciones:

- Tienen unas propiedades que han sido transferidas desde el sistema de origen al sistema de destino (Marinescu 2004), por lo que no siempre es posible desvincularlas.

- Aunque reflejen la realidad y tengan una base objetiva, constituyen una ficción, ya que en su proceso de creación hay una necesaria alteración de sus elementos.

- Requieren coherencia interna y un anclaje con los dominios de conocimiento compartido por los potenciales destinatarios, para que sea posible su comprensión.

- En tanto que metáforas dependientes de la subjetividad de emisor y receptor, pueden ser interpretadas de una forma diferente a la inicialmente prevista por su creador.

- Tienen un alto grado de sintetización, ya que condensan y relacionan diversos aspectos de su contenido en una única imagen o símbolo.

- Constituyen una abstracción cognitiva multidireccional y susceptible de incluir todos los lenguajes y metalenguajes existentes o futuros.

- Revelan las nuevas percepciones identitarias que tienen los individuos (Turkle 1997), que proyectan su yo consciente o inconsciente en ellas.

- Dada la facilidad de su manipulación, las imágenes son cada vez más conceptuales que informativas.

- Dada la facilidad de creación, acceso y transmisión, se pierde la tradicional secuencialidad y se impone una cultura de la fragmentación, del detalle.

- El flujo continuado y la velocidad en la generación de nuevas imágenes impide la reflexión profunda que caracterizaba la era Gütemberg.

\section{Diferencias entre las representaciones en la Web y en el Metaverso}

En función del entorno para el que son diseñadas estas representaciones o metáforas visuales tienen diferencias importantes. Así, dentro de un entorno virtual podemos señalar algunas de las que se producen entre la Web y el Metaverso (término acuñado por Stephenson en 1992 con su novela Snow Crash) a diferentes niveles:

\section{A nivel tecnológico y estructural:}

- En la Web el usuario se representa y actúa por sí mismo en un entorno cambiante (puede modificar forma y contenido) aunque homogéneo (estructura inalterable, ya que alberga los algoritmos que la sustentan).

En cambio, en el Metaverso el usuario está representado por un avatar (representación tridimensional a modo de entidad delegada pero no desvinculada) que goza de una cierta autonomía (puede adoptar una posición estática o dinámica) para actuar dentro de los denominados mundos espejo (formados por simulaciones detalladas del mundo real) en una actividad que puede ser de tipo inmersivo, lúdico o social.

- Los sitios Web (especialmente las páginas personales) están diseñados de acuerdo con las preferencias de su propietario o usuario (decide sus características técnicas y estéticas) ya que es éste quien los gestionará (los mantendrá actualizados) y los administrará (controlará los cambios).

Los Metaversos también están diseñados y construidos de acuerdo con las preferencias del propietario o usuario, pero éstos no siempre podrán controlar de una manera eficiente la estética final de su entorno o lugar, que puede verse alterada por la acción voluntaria o involuntaria de otros.

A diferencia de la Web, en la que el paso de visitantes no modifica la estructura ni la estética de la página (la interacción puede ser permitida, moderada o negada), en el Metaverso los visitantes tienen presencia y apariencia, pueden aportar objetos que quedan en el lugar (salvo que se incluyan restricciones de rezzeo) y todo ello puede incidir sobre el paisaje y/o afectar la capacidad del lugar.

A nivel operacional:

- En la Web, el usuario suele trabajar de forma individual. Aunque interactúe en las redes sociales o a través de mecanismos de videoconferencia, él es el único que controla su escritorio (salvo que ofrezca permisos de compartición), por lo que en todo momento es responsable de lo que ocurre en su pantalla.

No ocurre lo mismo en el Metaverso. En ellos, la forma de trabajo más habitual es la colaborativa, es decir, en grupos abiertos en los que, independientemente del grado de participación de cada usuario, todos se sienten integrantes de una misma comunidad virtual (término acuñado por Rheingold en 1993, en su libro The Virtual Community), definida como una asociación informal que fomenta nuevas prácticas sociales, fortalece vínculos, potencia las capacidades individuales, genera nuevas formas de interacción social y que redescubre y actualiza otras ya existentes en la vida real. - Pese a que la Web cada vez tiene más componentes gráficos, sus contenidos están mayoritariamente basados en el lenguaje escrito y dirigidos a movilizar el intelecto, cosa que implica una necesaria alfabetización previa.

En el Metaverso, el lenguaje es básicamente visual y simbólico, por lo que requiere, al menos aparentemente, una menor alfabetización previa para ser comprendido. A lo largo de la vida el hombre aprende a simbolizar y memorizar todos sus estímulos visuales. Así se han podido construir todos los lenguajes y metalenguajes utilizados diariamente, y que son o pueden ser distintos en cada comunidad.

\section{A nivel informacional:}

- En la Web existe una ingente cantidad de información (de carácter enciclopédico y experiencial) que circula a través de bits y que es procesada y servida por la propia máquina (ya sea a petición del usuario o de una forma pasiva por la acción de los internautas), alterando la estructura comunicacional clásica e inci- 


\begin{tabular}{|l|l|l|l|}
\hline Elementos & Mundo físico & Web & Metaverso \\
\hline Fuente & Persona / Entorno / Otras personas & Usuario / Red / Otros usuarios & Usuario / Entorno /Otros usuarios \\
\hline Emisor & $\begin{array}{l}\text { Persona y elementos del contexto fí- } \\
\text { sico (signos, símbolos, iconos, ...) }\end{array}$ & $\begin{array}{l}\text { Procesadores de datos, busca- } \\
\text { dores, sistemas de agregación, } \\
\text { recursos, ...) }\end{array}$ & $\begin{array}{l}\text { Avatar y elementos del contexto } \\
\text { virtual (elementos y recursos so- } \\
\text { noros, Figuras ...) }\end{array}$ \\
\hline Mensaje & Información & Datos e Información & Información \\
\hline Canal & Ondas y la propia persona & Internet & Internet \\
\hline Receptor & Persona & Repositorio de contenidos & Avatar \\
\hline Destinatario & Persona & Usuario & Usuario \\
\hline Contexto & Físico & Virtual, en dos dimensiones & Virtual, en tres dimensiones \\
\hline Ruido & Perturbaciones físicas & Granularidad (densidad) & Granularidad (densidad) \\
\hline
\end{tabular}

Tabla 1. Los elementos comunicativos en el mundo real y virtual.

diendo sobre las formas de pensar y de vivir (Manovich 1998), cosa que supone un cambio importante en el proceso comunicativo, ya que es la máquina la que actúa como emisor.

No ocurre lo mismo en el Metaverso. Aunque éste permite el acceso a la Web, no dispone de un repositorio de información propio, por lo que ésta ha de ser obtenida a través de un intercambio básicamente síncrono entre los avatares. En este caso la tecnología intermedia la acción, pero no influye en la obtención del significado, ya que, a diferencia de lo que ocurre en la Web, el procesador de dicha información no es la máquina sino el ser humano, al igual que sucede en el mundo físico o real.

- Web y Metaverso ofrecen unas referencias visuales metafóricas que actúan como contexto informacional, y que pueden tener un carácter:

- Estático: representación de una información inamovible como son las fotografías, mapas, diagramas, etc.

- Dinámico: sucesión de unas imágenes estáticas que, pasadas a una determinada velocidad, sugieren movimiento, caso del vídeo o de las machinimas.

- Actualizable, una combinación de imágenes estáticas y dinámicas que comparten un mismo plano para ofrecer una información continua y renovada de una situación: cotizaciones de bolsa, videoconferencias, retransmisiones vía streaming, etc.

Todas estas imágenes pueden tener un complemento gráfico o sonoro que ayuda a obtener los significados (leyendas o anotaciones en el chat, en las estáticas; voz o música, en las dinámicas; y una combinación de ambas, en las actualizables).

Pero mientras que la sonoridad sobre imágenes estáticas o dinámicas está editada previamente y, por tanto, está controlada, en las actualizables, al producirse de forma síncrona, el usuario pierde el control de la acción y pasa a convertirse en un receptor que trata de procesar las imágenes para obtener significados.

- Cuando se realiza una videoconferencia o una retransmisión vía streaming, la voz (en tiempo real) está complementada por imágenes también reales que aportan referencias de contexto (indicadores y relaciones) similares a las que obtendríamos en un entorno físico real.

Sin embargo, en el Metaverso, la voz (real y sincrónica) va asociada al avatar y, por ello, circunscrita a una realidad metafórica que aporta unas referencias contextuales que no son las del mundo físico, sino las del entorno virtual que soporta la acción. En consecuencia, el Metaverso inevitablemente ofrece una realidad mixta que concentra los elementos relevantes de la real y la virtual. - Pueden darse algunas circunstancias que en el mundo real serían inasumibles o incluso conflictivas y, que, por contra en el Metaverso son consideradas normales, demostrando la gran capacidad y predisposición del usuario para valorar cada situación de una manera distinta en función del entorno en el que está inmerso, priorizando aquellas partes que le son relevantes y despreciando de una forma consciente o inconsciente aquellos elementos perturbadores (ruido). Ejemplo de ello sería una situación en el que un avatar está hablando de una forma viva y sugerente pero, en cambio, ofrece una imagen de inactividad, o cuando un avatar de un aspecto desagradable para el usuario ofrece ayuda a los recién llegados.

De todo ello se deduce que hay una alteración de las funciones tradicionales de los elementos que intervienen en un proceso comunicativo, reflejados en la Tabla 1.

Se modifican algunos procesos comunicativos como:

- La emisión de la información. En la Web el emisor es la máquina que puede ser programada para que avise cuando se recibe un nuevo correo o un nuevo mensaje, cuando se ha publicado un post, unas dispositivas o un video que se ajusta a unos parámetros previamente seleccionados (autor, tema, etiqueta, etc.). La Web, además, ofrece al usuario respuestas a las preguntas formuladas a través de buscadores, redes sociales, etc.). En el Metaverso, en cambio, el emisor es el avatar (que actúa en representación del usuario) mediante la voz, el texto escrito o una creación metafórica de su idea. La información que genera no es distribuida automáticamente por la máquina, sino que requiere la intencionalidad de un usuario.

- Procesamiento de la información. La Web mantiene una estructura precisa, basada en unos algoritmos eficientes que, independientemente de la voluntad del usuario, logran que sea el sistema (la máquina) el que procese la información y la reprocese tantas veces como sea necesario para ofrecer unos significados adaptados a las necesidades del usuario, en pocos segundos. El Metaverso también está sustentado en una estructura matemática y en unos algoritmos, pero 
éstos no actúan sobre la información sino sobre los objetos y/o sobre el propio avatar, regulando las funciones que éstos pueden hacer en función de la voluntad o las necesidades del usuario. En ambos casos, para obtener el significado es preceptivo que el usuario determine la relevancia del mensaje en función de sus intereses o necesidades.

- Recepción de la información. Las imágenes no están sujetas a un código sígnico que ayude a crearlas o a interpretarlas, por tanto, la obtención de significados está directamente relacionada con los conocimientos previos del receptor y del grado de coincidencia entre los referentes de la fuente y el destinatario.

A nivel contextual:

- En la Web la visión se limita al marco de la pantalla. En el Metaverso, en cambio, esta limitación no existe, puesto que el avatar puede desplazarse permanentemente y la cámara recoge su mirada panorámica o detallada.

- En la Web la imagen suele ser un complemento del texto, pero también puede estar complementada por un texto o un audio que ayuda a interpretarla. En el Metaverso, la imagen es el contexto en el que se desarrolla la acción.

- A diferencia de la Web donde, por las limitaciones del entorno, no se explicitan las referencias contextuales, en el Metaverso algunos factores como la estética y los movimientos de cada avatar aportan unos datos e información complementaria que permite interactuar de una forma más eficiente, y también más parecida a la que se produce en un entorno físico, aunque lógicamente hay un margen permitido de error en la interpretación.

\section{A nivel de lenguaje:}

- Las imágenes son universales, no requieren lenguajes ni alfabetizaciones previas. Sin embargo, las representaciones conceptuales, con frecuencia necesitan de un soporte explicativo, que puede ser escrito o mediante el audio pero siempre basado en un idioma.

La Web dispone de traductores para fragmentos de texto o páginas enteras, pero no en tiempo real, como ocurre en el Metaverso. En Second Life existe un traductor, basado en el de Google, que traducen el chat escrito hasta en 52 idiomas de una forma bi/multi-direccional y en tiempo real, facilitando la comprensión del mensaje.

\section{La metáfora de NANEC2010/11}

Uno de los objetivos de NANEC2010/11 era mostrar de una manera práctica los postulados de las teorías constructivista y conectivista, de manera que los estudiantes las pudieran valorar desde un punto de vista teórico, pero también práctico.

El constructivismo se basa en la idea de aprender mediante la práctica, ya sea mediante entornos reales o simulados. A medida que se actúa es necesaria una constante toma de decisiones de la que se pueden extraer conclusiones y aprender. Los entornos simulados permiten errar en la toma de decisiones sin que se produzcan las inevitables consecuencias negativas que tendría en un contexto real, por tanto, la experimentación puede ser mucho más extensa y enriquecedora, y tener carácter individual o grupal. Por su parte, el conectivismo añade que este aprendizaje tiene carácter social cuando se apoya en la interacción y el trabajo colaborativo.

Tomando estas referencias como marco de actuación, y que todos los estudiantes inscritos en el curso son docentes, se diseña una simulación de contexto educativo, representado mediante una metáfora visual de carácter tridimensional en la que los estudiantes deben aprender por inmersión.

En este proceso de construcción de una realidad ficticia que soporte la simulación el avatar se constituye en un intermediario esencial que permite la inmersión, focaliza la acción y flexibiliza los límites entre ficción y realidad.

\section{Conocimiento del nuevo entorno virtual}

NANEC2010/11 tiene 178 estudiantes inscritos, que parten con un nivel conceptual y tecnológico dispar, aunque se podrían englobar en dos grupos:

1) Una tercera parte de los alumnos (de ahora en adelante lo llamaremos Grupo A) nunca había accedido a Second Life ni conocía otros entornos similares.

2) Unas dos terceras partes de los alumnos (lo llamaremos Grupo B) tenía un conocimiento teórico de los entornos virtuales y había experimentado en alguna ocasión sus usos, aunque no desde un punto de vista de educación formal.

Previendo este posible escenario, y especialmente dirigido al Grupo A, la primera actividad del curso fue un doble taller introductorio al nuevo entorno, impartido por Paz Villar. En su primera parte (por videoconferencia desde Elluminate) se informa de las características de Second Life y de
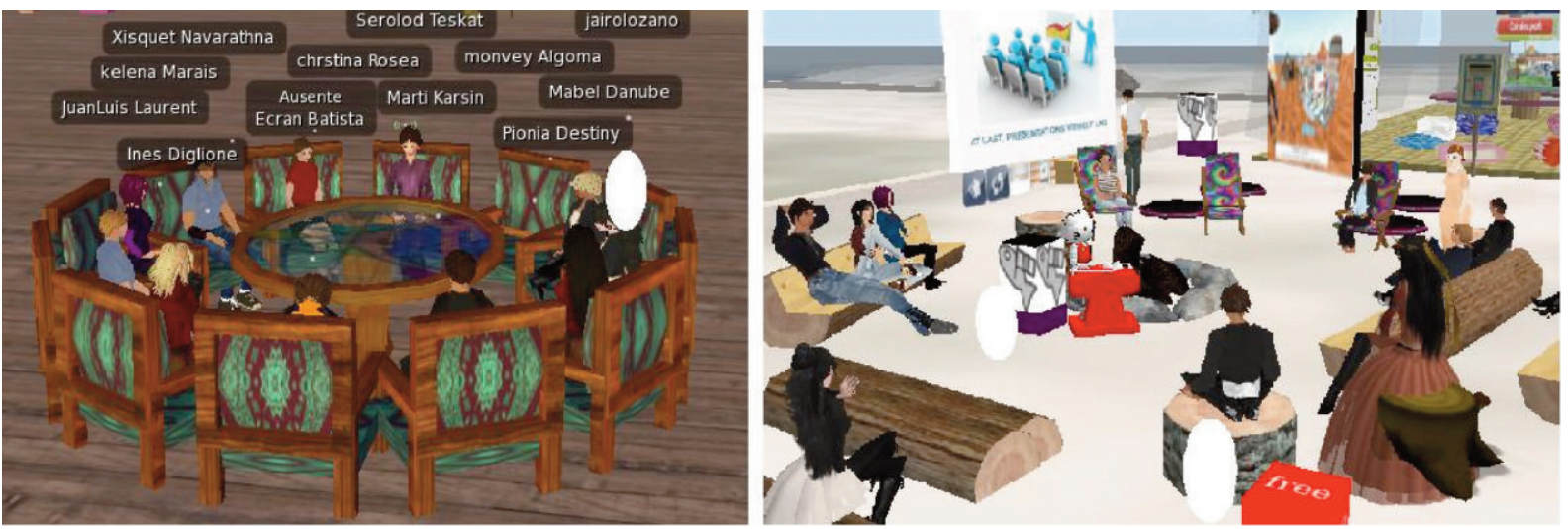

Figura 3. En la imagen de la izquierda se muestra un momento al inicio de una sesión de tutoría cuando los asistentes van llegando. Tras una introducción nos desplazamos a la sede de los Webers para recibir un taller sobre modos de aprendizaje, que se recoge en la imagen de la derecha. 
la forma de registro y acceso. En la segunda parte, ya desde dentro de Second Life, se dan las indicaciones básicas de uso para poder seguir con normalidad las sesiones de tutoría previstas a lo largo del curso. Se practican aspectos como:

\author{
- Movimiento de avatar \\ - Desplazamientos (teleporte) \\ - Utilización del chat escrito \\ - Utilización de la voz \\ - Envío de mensajes privados (IM) \\ - Creación de notas (Notecards)
}

Esta adquisición de habilidades es reforzada una semana después con un nuevo taller impartido por Dolors Capdet, y ampliada tres semanas después con una nueva sesión preparada por Doris Molero y Ana Begonia.

\section{Contexto virtual y referentes físicos}

Se pretende recrear un contexto de trabajo lo más similar posible a la realidad, en este caso y teniendo en cuenta que los estudiantes son docentes, es un aula presencial o física, donde los alumnos pueden establecer conexión visual y verbal con el profesor y el resto de alumnos (Figura 3). Para ello basta una mesa, unas sillas y la utilización de la voz. El chat escrito es utilizado a modo de pizarra para reforzar conceptos.

Se produce una rápida asimilación de la realidad simulada. Los avatares, que ya han aprendido a moverse, se sientan en una de las sillas, atienden a las explicaciones del profesor, preguntan, comentan, etc., de la misma manera que lo harían en una aula física. Para no solaparse en el uso de la voz, controlan las rayas verdes indicadoras de la activación de voz que aparecen sobre cada avatar cuando tiene el micrófono abierto. Cuando no disponen de micrófono utilizan el chat escrito para hacer llegar sus preguntas o consideraciones.

Por tanto, en este caso, el nuevo escenario, de acuerdo con las apreciaciones de Marianescu y Turkle descritas anteriormente, constituye una metáfora visual, ya que:

- Se produce una representación de una cosa (situación educativa presencial) en términos de otra (situación educativa virtual)

- Hay una clara transferencia de propiedades desde el sistema de origen (aula física) hacia el sistema de destino (Second Life), manteniendo vinculadas ambas realidades.

- Aunque este nuevo escenario refleja la realidad y tiene una base objetiva, constituye una ficción, puesto que hay una alteración de las propiedades de sus elementos (no es igual una silla o una mesa real que virtual).

- La representación del nuevo escenario tiene una coherencia interna y un anclaje con los dominios de conocimiento compartido, que facilita su comprensión (saben cómo es y para qué sirve un aula física y comprueban que la virtual permite usos similares)

- La aceptación de la representación como una realidad es posible gracias a la subjetividad del alumno. Los estudiantes de NANEC2010/11 la aceptan ya que permanecen dentro de ella hasta final de curso, de una forma natural, como si fuera algo habitual en sus vidas.
- Pese a que los elementos (imágenes y símbolos) que utiliza NANEC2010/11 son simples (mesa, sillas, etc.) y que inicialmente están desvinculados entre sí (se puede utilizar un número indeterminado y variable de mesas o de sillas), se integran en una representación visual sintetizadora que contiene aspectos como la posibilidad de inmersión, la utilidad y funcionalidad de la representación en una única imagen integrada que simboliza la acción (sesión de tutoría).

- En este nuevo escenario coinciden distintos lenguajes (verbal, escrito,) y metalenguajes (simbólico, algorítmico) que todos los implicados utilizan de una forma consciente o no. Por tanto, la acción tiene un carácter multidireccional.

- Se revelan las nuevas percepciones identitarias de tipo individual (plena identificación con el propio avatar que se modela según las propias preferencias). ${ }^{1}$

\section{De la subjetividad de la imagen a la realidad de la voz} En todo este proceso la voz resulta un elemento esencial, ya que dota al avatar de una identidad mixta: virtual (imagen) y real (voz asociada a la imagen).

Los estudiantes proceden de 14 países distintos, por tanto, no han tenido ocasión de conocerse en un contexto físico. Por ello, la imagen que se asocia a la voz es la del avatar y el nombre que se asocia a este conjunto es el del avatar. Por tanto, el avatar suplanta la identidad del usuario real (se mueve, habla, escribe, responde, ríe, llora, etc.). Tanto es así que a los usuarios más activos suelen ser reconocidos sólo por el nombre de su avatar.

Aceptada la nueva realidad, se establece un conjunto de relaciones sociales (interacción) que da cohesión y permite al estudiante trabajar de manera:

- Grupal, cuando trabaja en un grupo con un número estable de miembros para alcanzar un objetivo (trabajo para la evaluación de cada módulo).

- Colaborativa, cuando trabaja dentro de un gran grupo en el que no todos participan de la acción. Sólo lo hacen cuando entienden que su aportación en relevante (respuesta a peticiones de ayuda por parte del avatar).

La voz les ayuda a relacionarse de una manera directa y real, utilizando las mismas expresiones que utilizan en un contexto físico, es decir, gestionando y procesando la información de la misma manera que lo hacen en el contexto real, y compartiendo los mismos códigos y referentes, cosa que valida la metáfora.

En NANEC2010/11 la voz es la principal portadora del mensaje, relegando así a la representación visual a un plano secundario, ya que los objetos, aunque referencian la acción, sólo son utilizados de forma experiencial, por lo que no tienen capacidad suficiente para influir sobre el mensaje.

En este sentido, la voz está plenamente integrada en la representación de la metáfora.

\section{Integración del contexto real en el entorno virtual} Uno de los objetivos de las tutorías de NANEC2010/11 es la integración de los estudiantes en un ambiente tridimensional de una forma fluida, primando el aspecto conceptual 


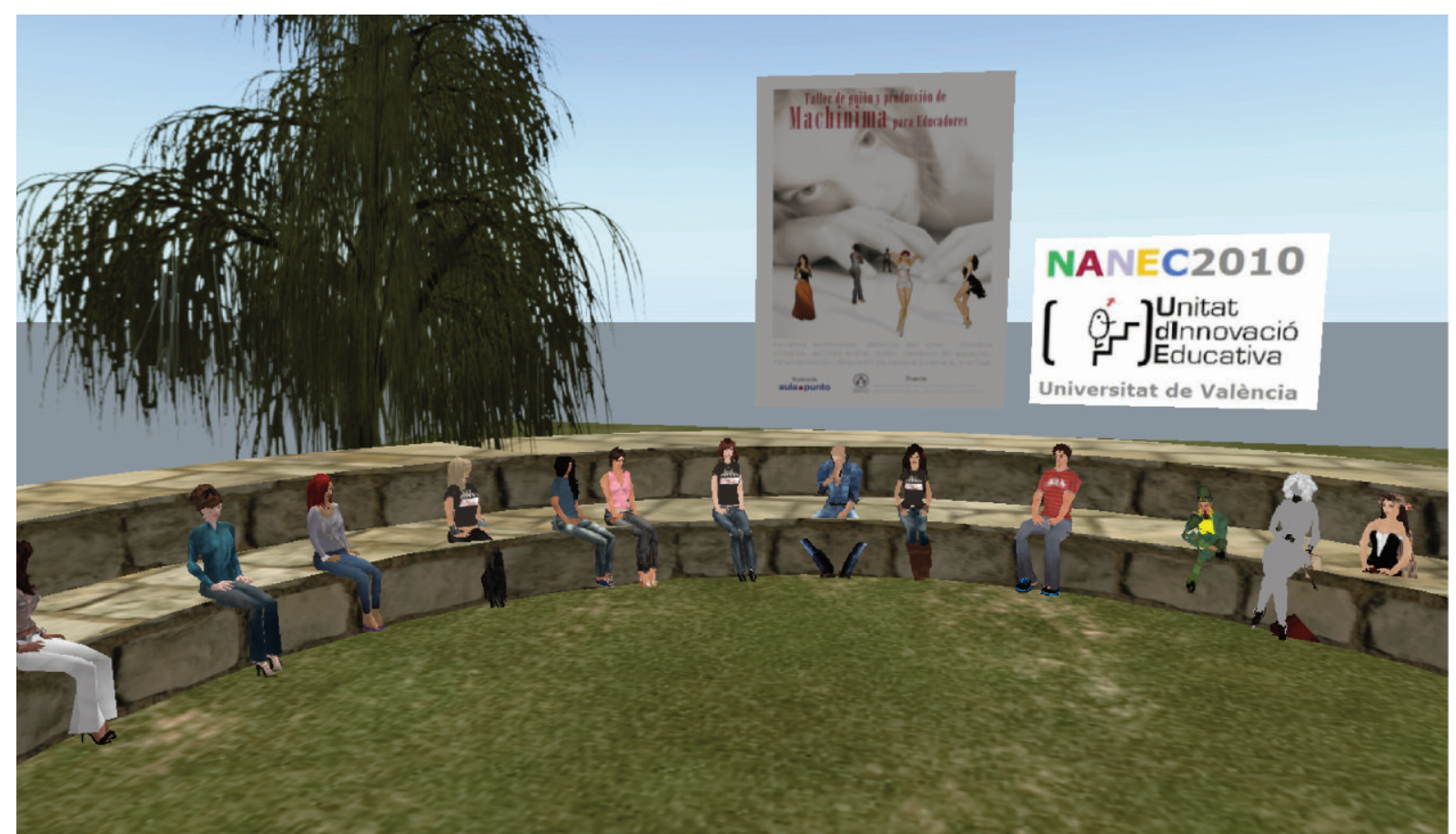

Figura 4. Foto del inicio del curso de Machinima y Streaming (lunes 13 de junio de 2011) cuya información está en este blog http://tallermachinima.blogspot.com/

sobre el tecnológico; por ello, sólo se utilizan elementos con un claro referente real. De esta forma se consigue que no haya ningún rechazo.

A medida que van asumiendo el nuevo entorno se van introduciendo elementos que no tienen un referente en el contexto real, con un componente lúdico, cosa que les permite poder disociarlos o no de la acción formativa, en función de gustos y preferencias personales.

Paralelamente a la acción formativa, los alumnos se preocupan de avanzar en su conocimiento del medio y de crear nuevas metáforas, que, quizá por mímesis con lo experimentado en el curso, se basan también en un traslado de situaciones del contexto real al virtual (selección de personal, comportamientos sociales, etc.).

Sólo se permiten utilizar la fantasía en el aspecto de su avatar, que entienden como parte subjetiva y propia (sentido de posesión). La situación en la que el avatar está inmerso en todo momento es entendida como social y, por ello, utilizan referentes conceptuales reales y códigos compartidos para que pueda ser comprendida por todos, aunque cada uno lo interprete a su manera.

\section{Integración de la ficción en el contexto real}

Con NANEC2010/11 se puede constatar que las representaciones metafóricas, que en sí mismas son pura ficción, una vez creadas se consolidan en su uso y adquieren carácter de permanencia, tal como se desprende de los siguientes datos:

- Participación sostenida a lo largo de las 22 sesiones de tutoría (una cada semana, salvo el lapsus navideño), con un media de participación de 30-35 alum- nos, que oscilan en cada sesión en función de sus necesidades puntuales, de carácter personal o profesional. Es necesario tener en cuenta que la participación en las sesiones de tutoría no era obligatoria y que el contenido de las mismas estaba básicamente dirigido a aclarar los conceptos expresados en las sesiones de los expertos (a través de Elluminate) y a reforzar los conceptos contenidos en el manual del curso (accesible desde la plataforma Aula Virtual de la Universitat de València). ${ }^{3}$

- Interacción constante, mantenida por los estudiantes dentro y fuera de las sesiones de tutoría. A medida interactuaban, se iban creando vínculos y se adquiría un sentimiento de pertenencia al grupo desde una concepción amplia que trasciende los límites y contenidos del curso.

- Colaborativismo. La interacción personal y el descubrimiento de un nuevo entorno con infinitas posibilidades, posibilita la colaboración personal, pero también la profesional, que en el caso de NANEC2010/11, se traduce la creación en junio de un curso de Machinima y Streaming (Figura 4), organizado por un grupo de alumnos (que son docentes de la Universitat de València); otro de Enseñanza y Aprendizaje en Entornos Virtuales, previsto para septiembre y organizado por la Universidad de los Ángeles de Chimbote (Perú); varias sesiones de trabajo como la que organiza en junio la Universidad Rafael Belloso Chacín (URBE), y otras que se están gestando en Argentina, Cuba o Colombia, sugeridas por algunos de los participantes de NANEC2010/11, que han visto un potencial práctico importante en este tipo de metáforas.

2 En estas diapositivas, presentadas en el Congreso VWBEP'11 como soporte de la ponencia relativa a NANEC2010/11,se refleja la actividad del curso: http://www.authorstream.com/Presentation/doris3m-912129-nanec2010-round-table/ 


\section{Conclusiones}

NANEC 2010/11 permitió confirmar algunos de los aspectos teóricos anteriores relativos a los mundos virtuales.

- Identidad: la voz junto a la presencia física de los avatares posibilitan la creación de una identidad digital individual y colectiva que permite trabajar colaborativamente.

- Contexto: actúa como una metáfora visual que ancla el entorno virtual con los referentes del entorno físico. Los objetos son utilizados de forma experiencial, pero no influyen sobre el mensaje. Las metáforas sólo son válidas cuando los referentes de fuente y destinatario coinciden y comparten intereses.

- Inmersión: el avatar es un intermediario creado con objeto de focalizar la acción, permitir la inmersión y flexibilizar los límites entre ficción y realidad.

- Comunicación: el usuario es quien procesa la información de forma análoga a la vida real, pero distinta a la Web, donde es la máquina quien procesa dicha información.

\section{Bibliografía}

Debray, Régis.(1998). Vida y muerte de la imagen. Historia de la mirada en Occidente. Traducción de R. Hervás. Barcelona: Paidós.

Gergen, Kenneth; Gergen, Mary. (2011). Reflexiones sobre la construcción social. Barcelona: Paidós

Gergen, Kenneth (2007). Construccionismo social, aportes para el debate y la práctica. Trad. de Angela María Estrada Mesa y Silvia Diazgranados. Bogotá: Universidad de los Andes, Facultad de Ciencias Sociales. http://publicacionesfaciso.uniandes.edu.co/psi/constr uccionismo_social.pdf .

Marianescu, Radu (2004). Detection strategies: Metrics-based rules for detecting design flaws.

http://ieeexplore.ieee.org/stamp/stamp.jsp?tp=\&ar number $=1357820$ \&userType $=$ inst $\quad$ Fecha de consulta: 14 de abril de 2011)
Manovich, L. (1998): Estética de los Mundos Virtuales. Revista El Paseante, núm. 27-28, p.95.

Rheingold, Howard (1993). The Virtual Community. Electronic version. 1993. En

http://www.rheingold.com/vc/book/intro.html (Fecha de conbsulta: 14 de abril de 2011)

Rivas, José Ignacio, Herrera, David., (Coords.) (2010). Voz y educación. La narrativa como enfoque de interpretación de la realidad. Barcelona: Octaedro. http://www.octaedro.com/pdf/16038.pdf (Fecha de consulta: 14 de abril de 2011).

Rosenwald, George C.; Ochberg, Richard L. (1992). Introduction: Life Stories, Cultural Politics, and Self-Understanding. En George C. Rosenwald y Richard L. Ochberg (Eds.), Storied Lives. The Cultural Politics of Self-Understanding . New Haven: Yale University Press.

Turkle, Sherry (1997). La vida en pantalla. Barcelona: Paidós.

White, Hayden (1987). El contenido de la forma. Barcelona: Paidós

| Cita recomendada de este artículo

Capdet, Dolors.Metáforas visuales en los mundos virtuales (2011). El caso de NANEC 2010/11. @tic. revista d'innovació educativa. (nº). URL. Fecha de consulta, dd/mm/aaaa. 